\title{
STABILITY OF GRAMMATICAL FEATURES OF BLACK SOUTH AFRICAN ENGLISH
}

Jean Parkinson \& Vanessa Singh

University of Kwa-Zulu Natal

This article explores the level of stability of some grammatical features of Black South African English (BSAE). The study involved testing a group of undergraduate speakers of BSAE using an exercise in which students judged the grammaticality of sentences and rewrote those they considered non-standard. Students were then alerted to grammatical differences between BSAE and Standard English (SE). Awareness of these differences developed during a student writing assignment in which BSAE features were discussed and compared with the standard forms, and students learnt to distinguish between SE and BSAE forms in assessing the rewritten sentences of their fellow students. After an interval of two months, the same participants were re-tested on their use of these features using a second similar grammaticality exercise. The results suggest that this minor intervention increased students' ability to recognise most of the non-standard forms and rewrite them in the standard form. This indicates present lack of stability in the BSAE variety, and is in line with previous findings (Van der Walt and Van Rooy, 2002) that BSAE is in a transition phase in which standard and BSAE forms are both regarded as options. The study also found also that some features of BSAE are more stable than others. The last part of the article considers qualitative data reflecting students' attitudes to BSAE and suggests that a sense of ownership of this variety might be an important step towards students' extending their repertoire to include a more formal written variety.

\section{Keywords}

BSAE; new varieties of English; student ownership of BSAE; stability of BSAE; academic discourse

\section{INTRODUCTION}

Black South African English (BSAE) is a new English variety that has been described by de Klerk (1999, 2003b), Gough (1996), Van der Walt and Van Rooy (2002), Van Rooy (2006) and Wade (1996) among others. Schmied (1991) views the variety of English spoken by people all over Southern Africa as similar enough to regard as one variety. At the other extreme, de Klerk (2003a, 2006) distinguishes between more restricted regional varieties such as Xhosa English. De Klerk (2003a) makes the point that considering the Englishes of speakers of a number of different languages as a single variety risks missing important differences. Others (e.g. Van Rooy, 2000) view the English of Black South Africans who have learnt English at school from BSAE-speaking teachers as distinctive enough to be viewed as a separate variety, BSAE. Van Rooy, (2000) and Van Rooy and Van Huysteen (2000) base this argument on phonetic considerations, reporting no difference between for example Xhosa English and Zulu English at a phonetic level. In this article, we take the stance 
that although there may indeed be grammatical variation reflecting region or first language, evidence for such variation is not presently available to us and for our purposes the English spoken by our participants, all mother tongue speakers of African languages in Southern Africa, is similar enough to be regarded as one variety: BSAE.

As a relatively new variety, it has been suggested (Van der Walt and Van Rooy 2002) that BSAE is still in the process of stabilising, or changing to a situation where there are well accepted norms in the grammatical features of the variety amongst the population that speaks the variety. In this article we probe this notion of stability, and use two measures of the stability of BSAE. The first, used previously by Gough (1996), Makalela (1998) and Van der Walt and Van Rooy (2002), concerns the ability of our subjects to recognise sentences containing BSAE constructions as non-standard and change them to the standard English (SE) form. Where this ability is common to most subjects tested, this is taken as a sign that the BSAE form has not stabilised as the norm. The second measure is the change in the proportion of our subjects who recognise as standard the SE forms after a relatively minor teaching intervention, indicating instability in our subjects' sense of what the standard version is.

It should be noted that the data for the study were collected as a consequence of a student assignment directed at teaching students how to write a laboratory report, and was not the result of an attempt to shift students' language variety in the direction of Standard English. The grammaticality exercise formed the data that our students used in writing their report. Before moving on to outline our study at greater length, we begin by summarising briefly some relevant studies of BSAE.

English is the mother tongue of only 8.2\% of South Africans (2001 census). However, English is widely used by speakers of African languages in South Africa, with most Black South African speakers of English speaking the BSAE variety. BSAE is not uniform and ranges from an educated variety to a fairly rudimentary form (de Klerk 1999). Kachru (1992) notes that this lack of uniformity in a language variety can be viewed either as a lectal range with three points on a continuum (acrolect, mesolect and basilect) or as a cline of bilingualism from an educated to a colloquial variety.

This study uses data collected from first year students at the University of KwaZulu-Natal. The students are relatively proficient in English, having completed most of their schooling through the medium of English, and all speak the BSAE variety, having learnt English from teachers who are themselves mother tongue speakers of an African language (see van Rooy, 2000). This means that BSAE has at least some of the features of what Williams (1987) has called Non-native Institutionalised Varieties of English (NIVE). Williams characterises such varieties, which are spoken by speakers with a wide range of mother tongues, as institutionalised, in that they are acquired through the education system. Being acquired from teachers who themselves are speakers of the variety, they also show stability and are not really learner varieties. Therefore, Williams (1987) notes, the grammatical forms of a NIVE will be resistant to being shifted in the direction of the standard variety through teaching.

Although it matches to a large extent the characteristics of a NIVE outlined by Williams (1987), BSAE may not yet have reached the level of stability that is implied in a NIVE. Using a three phase model of norm development (Gill 1999), Van der Walt and Van Rooy (2002) maintain that BSAE is currently in a transition phase, between moving from a situation where all members of the linguistic community accept an external norm to one in which an internal norm is accepted by all. In this transition phase, there is inconsistency and uncertainty about 
norms, with both standard and non-standard forms accepted. Van der Walt and Van Rooy (2002) found that while certain non-standard constructions (for example resumptive pronouns) are judged unacceptable by teachers who are themselves speakers of BSAE, many other constructions (including use of prepositions, quantifiers and articles) both standard and non-standard learner constructions were accepted by the teachers in their study. Our study supports this lack of certainty about norms. We found that our students use both SE and BSAE as optional forms, and that a relatively minor intervention, which we describe below, convinced many to select the SE form as the norm in a test situation. We use this fluidity as an indicator of instability of BSAE.

The grammatical and other features of BSAE have received increasing attention from researchers. Examining the case of Xhosa English, De Klerk (2003b) notes that two principles, which work against each other, are evident in Non-native Institutionalised Varieties of English: those of economy and hyperclarity. One example of the economy principle that represents regularisation or lack of recognition of exceptions is use of the progressive with stative verbs (Some people are believing in God) ${ }^{1}$. Another is keeping the question order in indirect questions (e.g. 'They wanted to find out how does it work'). An example of hyperclarity is the double use of the subordinators although ... but ... (Although nuclear power can be very destructive but it can produce benefits). The notion of hyperclarity has similarities with Mesthrie's (2006) analysis of BSAE as a variety favouring anti-deletion. He notes that BSAE restores features that are deleted in modern English (e.g. That thing made me to know God), as well as inserting additional morphemes as in the although ... but example quoted above.

In generating our own data, we drew on the small studies done by Gough (1996) and Makalela (1998). Both Gough (1996) and Makalela (1998) tested the ability of English teachers, speakers of the BSAE variety, to rewrite sentences containing BSAE constructions into Standard English. They found that some constructions were successfully rewritten by most of the teachers in their samples, while others were accepted as standard by most of their subjects and were thus concluded by them to be more stable features of BSAE. In our research, which we describe below, we measure stability not only as a function of whether a feature is accepted as standard by most people, but also in terms of the extent to which speakers of the variety are willing to move along the cline from the more colloquial BSAE to the more formal Standard form in what they recognise as grammatically correct. Our study extends Gough (1996) and Makalela (1998) in the sense that we test the stability of the features of BSAE by using a brief intervention making our subjects aware of the two varieties. This intervention is described in what follows.

\section{METHOD}

The students in our study, who were all speakers of BSAE, and largely mother-tongue speakers of Zulu, had just finished school and their age range was 17 to 19 years with a small minority in their early twenties. Students were first year Science students, registered for the academic literacy course described below.

The data we present in this article was collected as a by-product of an assignment done by our students. The purpose of the assignment was that the students should learn to write a laboratory report, the most prominent pedagogic genre in science. The focus of the course is acquisition of academic genres prominent in Science: the laboratory report and the essay. It is 
not the purpose of the course to provide formal teaching of grammatical constructions or to train our students to 'correct' their dialect to Standard English.

To give more insight into the assignment that was the source of our data, the assignment asked students to consider the question of whether BSAE should be made the Standard English of South Africa. In answering this question they tested the members of the class using the sentences reflected in Tables 1 and 2. They used the data generated in this way to establish what some of the grammatical features of BSAE are. They then made an assessment of what proportion of the class regarded these features as standard. Tutors provided the Standard English version of each sentence for comparison, but made no attempt to convince students that Standard English was preferable to BSAE. This assignment constituted a first time encounter for the students with the distinction between the BSAE and SE forms as representing two different varieties rather than being optional equivalents.

For the purposes of our study, we retested the students two months later using different but similar sentences. We wanted to see if being alerted to the fact that one of the versions of the various constructions was regarded as standard had any effect on students' ability to produce the standard construction. We are aware that a sentence-correction exercise is artificial, and is no indication that students' writing in general will be shifted by this exercise in the direction of Standard English. What a change shows is that both forms are part of the students' repertoire and that they have become consciously aware that one form is the SE form and the other the BSAE form.

The data collected for this research is the result of two tests. Test 1 was written in August and Test 2 in October for five consecutive years:

\begin{tabular}{|l|l|}
\hline Year & Number of students writing the tests \\
\hline 2002 & 42 \\
\hline 2003 & 79 \\
\hline 2004 & 20 \\
\hline 2006 & 36 \\
\hline 2007 & 44 \\
\hline Total & 221 \\
\hline
\end{tabular}

The sentences in the August and October tests are reflected in Tables 1 and 2. The sentences in the August test were taken from Gough (1996) and Makalela (1998), in order to facilitate a comparison with their results. An attempt was made to match the sentences in the October test in terms of level of grammatical complexity. It will be noted that more examples of each feature were included in Test 2 compared to Test 1 . The reason for this is that even slight variations in grammatical complexity, as well as unfamiliar vocabulary make it less likely that students will identify the particular feature being focused on. We wanted Test 2 to make allowance for unexpected difficulty experienced by subjects. In both tests students were asked to rewrite in Standard English those sentences that they felt were not standard, but to leave nchanged the ones they felt were already written in standard form.

Our research involved three stages:

1. In August, we tested the students' ability to rewrite into SE a number of sentences each reflecting a different BSAE construction (see Table 1 for a list of sentences used in the tests). 
2. Students 'marked' the tests of all their fellow students (in order to collect data for the assignment they were writing). This required that students repeatedly compare the Standard and BSAE forms of the different constructions in order to make a judgment about whether or not each of their fellows had produced the SE or BSAE variety.

3. In October we retested students on these constructions (using different sentences).

\section{DISCUSSION OF RESULTS}

In the Introduction above we raised the question of how stable BSAE is. In the discussion that follows we use the proportion of our sample who regard the BSAE version of a grammatical feature as standard before doing the assignment as a measure of how stable a feature is. Gough (1996) and Makalela (1998) too note that when a BSAE feature is selected as standard in preference to the SE form, this indicates stability for the BSAE feature. As a second measure, we use any change between August (before the assignment) and October (after the assignment) in the proportion of students who regard a feature as standard as a measure of instability in the BSAE feature.

Table 1 entitled 'Is there a shift from BSAE to SE between August and October', shows that for eight out of thirteen features, in August, before the intervention, the majority of our students regard the BSAE form as standard. For five of the features however, most students altered the BSAE form to the Standard form, meaning that these cannot, by this measure, be regarded as stable features of this language variety. These features include:

- Topicalisation (e.g. 'This issue I will tell my children and grandchildren'.)

- Marking of past tense (e.g. 'In 1980 the boycott starts'.)

- Use of resumptive pronouns (e.g. 'The man who I saw him was wearing a big hat'.)

- Omission of indefinite article (e.g. 'He was good man'.)

- Use of 'in order that' in purpose clauses (e.g. 'He went there in order that he sees her'.)

However, it appears that the intervention (alerting students to the two forms of these grammatical features) did have some effect on the students. In the case of nine out of the thirteen grammatical features, there was a shift towards standard norms between August and October, after the intervention. A z-test was used to test significance, and the shift was found to be statistically significant at the $95 \%$ level. The nine features for which there was a shift towards Standard English include:

- Use of the progressive in situations that are not of limited duration (e.g. 'Many people are believing in God'.)

- Simplification of modal auxiliaries (e.g. 'I wish that people in the world will get educated'.)

- Use of the subordinators 'Although ... but' (e.g. 'Although she loved him but she did not marry him')

- Use of 'can be able to' as a phrasal equivalent of 'can' (e.g. I can be able to go'.)

- Question order retained in indirect questions (e.g. 'I asked him why did he go'.)

- Use of quantifiers (we focus on use of 'others...others' rather than 'some...others)

- Topicalisation

- Marking of past tense

- Patterns of complementation ('made me to know...') 
$J$ Parkinson \& V Singh

Table 1: Is there a shift from BSAE to SE between August and October?

\begin{tabular}{|c|c|c|c|c|c|c|c|c|c|c|c|}
\hline \multirow{3}{*}{ Feature } & & \multirow{3}{*}{ Sentence used in test } & \multirow{3}{*}{$\begin{array}{l}\text { Gough } \\
(1996) \\
\mathrm{N}=20\end{array}$} & \multirow{3}{*}{$\begin{array}{l}\text { Makalela } \\
(1999) \\
\mathrm{N}=20\end{array}$} & \multirow{3}{*}{$\begin{array}{l}\text { Total on } \\
\text { which } \\
\text { comparison } \\
\text { is based } \mathrm{N}=\end{array}$} & \multicolumn{4}{|c|}{$\begin{array}{l}\text { Number and \% who successfully } \\
\text { changed the sentence to SE }\end{array}$} & \multicolumn{2}{|c|}{ Significance test } \\
\hline & & & & & & $\begin{array}{l}\text { Aug } \\
2002, \\
04,05, \\
06\end{array}$ & $\begin{array}{l}\text { Aug } \\
2002, \\
0405, \\
06 \%\end{array}$ & $\begin{array}{l}\text { Oct } \\
2002, \\
04,05, \\
06\end{array}$ & $\begin{array}{l}\text { Oct } \\
2002, \\
04,05, \\
06 \%\end{array}$ & $\begin{array}{l}\mathrm{H}_{0}=\text { no } \\
\text { between } \\
\text { October. } \\
\mathrm{Z}<-1.64\end{array}$ & $\begin{array}{l}\text { hange } \\
\text { August and } \\
\text { Reject } \mathrm{H}_{0} \text {; if }\end{array}$ \\
\hline & & & & & & & $\mathrm{p}_{1}$ & & $\mathrm{p}_{2}$ & & SE \\
\hline \multirow{5}{*}{$\begin{array}{l}\text { Use of the } \\
\text { progressive in } \\
\text { situations that are } \\
\text { not of limited } \\
\text { duration }\end{array}$} & Aug & Some viruses are causing cancer & & & $\mathrm{n}_{1}=64$ & 21 & $33 \%$ & & & & \\
\hline & Oct & Many people are believing in God & & & $\mathrm{n}_{2}=63$ & & & 50 & $79 \%$ & -5.28 & yes \\
\hline & Oct & People are preferring to live in cities & & & $\mathrm{n}_{2}=44$ & & & 34 & $77 \%$ & -4.7 & yes \\
\hline & Oct & The constitution is not allowing capital punishment & & & $\mathrm{n}_{2}=44$ & & & 27 & $61 \%$ & -2.93 & yes \\
\hline & Oct & Usually I am going home on Fridays & & & $\mathrm{n}_{2}=44$ & & & 40 & $91 \%$ & -5.98 & yes \\
\hline \multirow{2}{*}{$\begin{array}{l}\text { Simplification of } \\
\text { modal auxiliaries }\end{array}$} & Aug & I wish that people in the world will get educated* & & & 142 & 36 & $25 \%$ & & & & \\
\hline & Oct & They wanted to test how long the machines will work & & & 141 & & & 57 & $40 \%$ & -2.7 & yes \\
\hline \multirow{4}{*}{$\begin{array}{l}\text { Double use of } \\
\text { subordinators } \\
\text { 'although...but' }\end{array}$} & Aug & Although she loved him but she didn’t marry him* & $95 \%$ & & 142 & 55 & $39 \%$ & & & & \\
\hline & Oct & $\begin{array}{l}\text { Although nuclear power can be destructive but it can also } \\
\text { produce benefits }\end{array}$ & & & 141 & & & 89 & $63 \%$ & -4.1 & yes \\
\hline & Oct & Although he worked hard but he did not pass & & & 44 & & & 34 & $77 \%$ & -4.47 & yes \\
\hline & Oct & Although snakes are dangerous but it's wrong to kill them & & & 44 & & & 33 & $75 \%$ & -4.21 & yes \\
\hline \multirow{3}{*}{$\begin{array}{l}\text { 'Can be able to' as } \\
\text { a phrasal } \\
\text { equivalent of 'can' }\end{array}$} & Aug & I can be able to go* & $65 \%$ & & 142 & 27 & $19 \%$ & & & \multirow{3}{*}{$\begin{array}{l}-6.76 \\
-4.88\end{array}$} & \\
\hline & Oct & Surveillance can be able to track anyone & & & 133 & & & 78 & $59 \%$ & & yes \\
\hline & Oct & He can be able to pass & & & 44 & & & 25 & $57 \%$ & & yes \\
\hline \multirow{4}{*}{$\begin{array}{l}\text { Question order } \\
\text { retained in indirect } \\
\text { questions }\end{array}$} & Aug & I asked him why did he go* & $95 \%$ & & 142 & 9 & $6 \%$ & & & & \\
\hline & Oct & They wanted to find out how does it work & & & 141 & & & 23 & $16 \%$ & -2.65 & yes \\
\hline & Oct & The teacher asked him why did he come late & & & 44 & & & 12 & $27 \%$ & -3.83 & yes \\
\hline & Oct & The policeman asked the man where does he live & & & 44 & & & 14 & $32 \%$ & -4.49 & yes \\
\hline \multirow{4}{*}{$\begin{array}{l}\text { Use of quantifier } \\
\text { 'others...others' }\end{array}$} & Aug & Others were drinking, others were eating & & & 142 & 10 & $7 \%$ & & & & \\
\hline & Oct & $\begin{array}{l}\text { Other methods of surveillance use cameras and others use } \\
\text { satellites }\end{array}$ & & & 141 & & & 55 & $39 \%$ & -6.39 & yes \\
\hline & Oct & Other animals are herbivores and others are carnivores & & & 44 & & & 13 & $30 \%$ & -3.96 & yes \\
\hline & Oct & Others live in residence and others live at home & & & 44 & & & 13 & $30 \%$ & -3.96 & yes \\
\hline
\end{tabular}


$J$ Parkinson \& V Singh

\begin{tabular}{|c|c|c|c|c|c|c|c|c|c|c|c|}
\hline \multicolumn{2}{|c|}{$\begin{array}{l}\text { Table } 1 \text { continued } \\
\text { Feature }\end{array}$} & \multirow{2}{*}{$\begin{array}{l}\text { Sentence used in test } \\
\text { This issue I will tell my children and grandchildren\# }\end{array}$} & \multirow[t]{2}{*}{$\begin{array}{l}\text { Gough } \\
(1996) \\
N=20\end{array}$} & \multirow{2}{*}{$\begin{array}{l}\text { Makalela } \\
\begin{array}{l}(1999) \\
\mathrm{N}=20 \\
\\
40 \%\end{array}\end{array}$} & \multirow[t]{2}{*}{$\begin{array}{l}\text { Total on } \\
\text { which } \\
\text { comparison } \\
\text { is based } \mathrm{N}= \\
142\end{array}$} & \multirow[t]{2}{*}{ 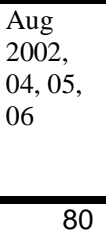 } & \multirow[t]{2}{*}{$\begin{array}{r}\text { Aug } \\
2002, \\
0405, \\
06 \% \\
p_{1} \\
\quad 56 \%\end{array}$} & \multirow[t]{2}{*}{$\begin{array}{l}\text { Oct } \\
2002 \\
04,05 \\
06\end{array}$} & \multirow[t]{2}{*}{$\begin{array}{l}\text { Oct } \\
2002 \\
04,05 \\
06 \% \\
\mathrm{p}_{2}\end{array}$} & \multicolumn{2}{|c|}{$\begin{array}{l}\mathrm{H}_{0}=\text { no change } \\
\text { between August and } \\
\text { October. Reject } \mathrm{H}_{0} \text {; if } \\
\mathrm{Z}<-1.645\end{array}$} \\
\hline Topicalisation & Aug & & & & & & & & & & \\
\hline & Oct & The exam it was not as difficult as I expected & & & 141 & & & 121 & $86 \%$ & -5.47 & yes \\
\hline & Oct & Wild animals, we need to conserve them & & & 44 & & & 43 & $98 \%$ & -5.07 & Yes \\
\hline \multirow{3}{*}{$\begin{array}{l}\text { Past tense not } \\
\text { always marked }\end{array}$} & Aug & In 1980 the boycott starts* & & & 142 & 113 & $80 \%$ & & & & \\
\hline & Oct & The school is built in 1990 & & & 44 & & & 42 & $95 \%$ & -2.47 & Yes \\
\hline & Oct & Mendeleev develops the periodic table in 1869 & & & 44 & & & 40 & $91 \%$ & -1.72 & Yes \\
\hline \multirow{3}{*}{$\begin{array}{l}\text { Patterns of } \\
\text { complementation } \\
\text { in 'make to...' }\end{array}$} & Aug & That thing made me to know God* & $55 \%$ & & 42 & 6 & $14 \%$ & & & & \\
\hline & Oct & Heat makes metal to expand & & & 86 & & & 11 & $13 \%$ & 0.234 & No \\
\hline & Oct & Studying at University makes me to know so many things & & & 44 & & & 18 & $41 \%$ & -2.75 & Yes \\
\hline \multirow{2}{*}{$\begin{array}{l}\text { Preposition usage } \\
\text { in prepositional } \\
\text { verbs }\end{array}$} & Aug & He explained about the situation* & $25 \%$ & & 142 & 36 & $25 \%$ & & & & \\
\hline & Oct & The lecturer explained about Newton's laws & & & 44 & & & 16 & $36 \%$ & -1.42 & No \\
\hline \multirow{2}{*}{$\begin{array}{l}\text { Use of resumptive } \\
\text { pronouns }\end{array}$} & Aug & The man who I saw him was wearing a big hat* & $100 \%$ & & 142 & 100 & $70 \%$ & & & & \\
\hline & Oct & My friend who you know her is coming to visit & & & 44 & & & 32 & $73 \%$ & -0.29 & No \\
\hline \multirow{2}{*}{$\begin{array}{l}\text { Articles: omission } \\
\text { of 'a' }\end{array}$} & Aug & He was good man* & $95 \%$ & & 142 & 125 & $88 \%$ & & & & \\
\hline & Oct & I have test tomorrow & & & 44 & & & 42 & $95 \%$ & -1.42 & No \\
\hline \multirow{3}{*}{$\begin{array}{l}\text { Use of 'in order } \\
\text { that' in purpose } \\
\text { clauses }\end{array}$} & Aug & He went there in order that he sees her* & & & 142 & 110 & $77 \%$ & & & & \\
\hline & Oct & $\begin{array}{l}\text { Surveillance is used in order that they stop terrorists } \\
\text { entering buildings }\end{array}$ & & & 141 & & & 116 & $82 \%$ & -1.01 & No \\
\hline & Oct & She studied hard in order that she gets a degree & & & 44 & & & 29 & $66 \%$ & & No \\
\hline
\end{tabular}

* Sentence from Gough (1996); \# Sentence taken from Makalela (1998). 
$J$ Parkinson \& V Singh

Table 2: How do our students compare to Gough's and Makalela's samples?

\begin{tabular}{|c|c|c|c|c|c|c|c|c|c|c|c|}
\hline \multicolumn{8}{|c|}{ Iable 2: How do our students compare to Gough s and Makalela s samples? } & \multicolumn{4}{|c|}{ Uctober } \\
\hline & & & & & & $\begin{array}{l}\% \text { success } \\
\text { to } \mathrm{SE}\end{array}$ & fully altered & $\begin{array}{l}\mathrm{H}_{0} \text { means } \\
\text { ours. Reje }\end{array}$ & $\begin{array}{l}\text { Makalela/ Goug } \\
\text { ct } \mathrm{H}_{0} \text { if } \mathrm{Z}>1.96\end{array}$ & $\begin{array}{l}\text { esults a } \\
Z<-1.9\end{array}$ & e the same as \\
\hline \multicolumn{2}{|l|}{ Feature } & Sentence used & $\begin{array}{l}\text { Gough } \\
(1996) \\
\mathrm{n}_{1}=20 \\
\mathrm{p}_{1}\end{array}$ & $\begin{array}{l}\text { Makalela } \\
(1999) \\
\mathrm{n}_{1}=20 \\
\mathrm{p}_{1}\end{array}$ & $\begin{array}{l}\text { Total on } \\
\text { which } \\
\text { comparison } \\
\text { is based } \\
\mathrm{n}_{2}\end{array}$ & $\begin{array}{l}\text { August } \\
2002, \\
0405, \\
06 \% \\
\mathrm{p}_{2}\end{array}$ & $\begin{array}{l}\text { October } \\
2002,04, \\
05,06 \% \\
\mathrm{p}_{2}\end{array}$ & $\mathrm{Z}$ & $\begin{array}{l}\text { Our } \\
\text { students } \\
\text { compared } \\
\text { to Makalela } \\
\text { /Gough? }\end{array}$ & $\mathrm{Z}$ & \begin{tabular}{|l} 
Our \\
students \\
compared \\
to Makalela \\
/Gough? \\
\end{tabular} \\
\hline \multirow{4}{*}{$\begin{array}{l}\text { Double use of } \\
\text { subordinators } \\
\text { 'although...but' }\end{array}$} & Aug & Although she loved him but she didn’t marry him* & $95 \%$ & & 142 & $39 \%$ & & 4.72 & $\begin{array}{l}\text { ours further } \\
\text { from SE }\end{array}$ & & \\
\hline & Oct & $\begin{array}{l}\text { Although nuclear power can be destructive but it can also } \\
\text { produce benefits }\end{array}$ & & & 141 & & $63 \%$ & & & 2.84 & $\begin{array}{l}\text { ours further } \\
\text { from SE }\end{array}$ \\
\hline & Oct & Although he worked hard but he did not pass & & & 44 & & $77 \%$ & & & 1.74 & same \\
\hline & Oct & Although snakes are dangerous but it's wrong to kill them & & & 44 & & $75 \%$ & & & 1.90 & same \\
\hline \multirow{3}{*}{$\begin{array}{l}\text { 'Can be able to' as } \\
\text { a phrasal } \\
\text { equivalent of 'can' }\end{array}$} & Aug & I can be able to go* & $65 \%$ & & 142 & $19 \%$ & & 4.46 & $\begin{array}{l}\text { ours further } \\
\text { from } \mathrm{SE}\end{array}$ & & \\
\hline & Oct & Surveillance can be able to track anyone & & & 133 & & $59 \%$ & & & 0.54 & same \\
\hline & Oct & He can be able to pass & & & 44 & & $57 \%$ & & & 0.62 & same \\
\hline \multirow{3}{*}{$\begin{array}{l}\text { Question order } \\
\text { retained in indirect } \\
\text { questions }\end{array}$} & Aug & I asked him why did he go* & $95 \%$ & & 142 & $6 \%$ & & 9.82 & $\begin{array}{l}\text { ours further } \\
\text { from SE }\end{array}$ & & \\
\hline & Oct & They wanted to find out how does it work & & & 141 & & $16 \%$ & & & 7.50 & $\begin{array}{l}\text { ours further } \\
\text { from } \mathrm{SE}\end{array}$ \\
\hline & Oct & The teacher asked him why did he come late & & & 44 & & $27 \%$ & & & 5.03 & $\begin{array}{l}\text { ours further } \\
\text { from } \mathrm{SE}\end{array}$ \\
\hline \multirow[t]{3}{*}{ Topicalisation } & Aug & This issue I will tell my children and grandchildren\# & & $40 \%$ & 142 & $56 \%$ & & -1.37 & same & & \\
\hline & Oct & The exam it was not as difficult as I expected & & & 141 & & $86 \%$ & & & -4.81 & $\begin{array}{l}\text { ours closer to } \\
\text { SE }\end{array}$ \\
\hline & Oct & Wild animals, we need to conserve them & & & 44 & & $98 \%$ & & & -5.32 & $\begin{array}{l}\text { ours closer to } \\
\mathrm{SE}\end{array}$ \\
\hline \multirow{4}{*}{$\begin{array}{l}\text { Patterns of } \\
\text { complementation } \\
\text { in 'make to...' }\end{array}$} & Aug & That thing made me to know God* & $55 \%$ & & 42 & $14 \%$ & & 3.36 & $\begin{array}{l}\text { ours further } \\
\text { from SE }\end{array}$ & & \\
\hline & Oct & Heat makes metal to expand & & & 86 & & $13 \%$ & & & 4.19 & $\begin{array}{l}\text { ours further } \\
\text { from } \mathrm{SE}\end{array}$ \\
\hline & Oct & Studying at University makes me to know so many things & & & 44 & & $41 \%$ & & & 1.05 & same \\
\hline & Aug & I tried that I might see her & $85 \%$ & & 121 & $56 \%$ & & 2.44 & $\begin{array}{l}\text { ours further } \\
\text { from } \mathrm{SE}\end{array}$ & & \\
\hline \multirow[t]{2}{*}{$\begin{array}{l}\text { Use of resumptive } \\
\text { pronouns }\end{array}$} & Aug & The man who I saw him was wearing a big hat* & $100 \%$ & & 142 & $70 \%$ & & 2.83 & $\begin{array}{l}\text { ours further } \\
\text { from SE }\end{array}$ & & \\
\hline & Oct & My friend who you know her is coming to visit & & & 44 & & $73 \%$ & & & 2.59 & $\begin{array}{l}\text { ours further } \\
\text { from SE }\end{array}$ \\
\hline \multirow{2}{*}{$\begin{array}{l}\text { Articles: omission } \\
\text { of 'a' }\end{array}$} & Aug & He was good man* & $95 \%$ & & 142 & $88 \%$ & & 0.93 & same & & \\
\hline & Oct & I have test tomorrow & & & 44 & & $95 \%$ & & & -0.08 & same \\
\hline $\begin{array}{l}\text { 'very much' as } \\
\text { intensifier }\end{array}$ & Aug & Hatred is very much common & $65 \%$ & & 177 & $26 \%$ & & 3.61 & $\begin{array}{l}\text { ours further } \\
\text { from } S E\end{array}$ & & \\
\hline Past not marked & Aug & We stayed in our home until the boycott stops\# & $30 \%$ & & 177 & $57 \%$ & & -2.25 & ours closer SE & & \\
\hline
\end{tabular}


This shift to selecting the SE form as standard indicates lack of stability in the subjects' English. This is particularly striking in that students in our study were given little explanation or teaching of the SE form. Teaching did not go beyond pointing out the SE form and contrasting it with the BSAE form. As indicated by Nwaila (1993) speakers of BSAE regard both SE and BSAE forms as standard. Similarly, our students were surprised to learn that the BSAE sentences in the test were regarded as non-standard. This is consistent with the findings of Coetzee-Van Rooy and Verhoef (2000) that learners rate their own proficiency in English as very high.

By contrast there was no statistically significant shift in:

- Use of resumptive pronouns

- Omission of the indefinite article

- Use of 'in order that' in purpose clauses

- Prepositional verbs (explained about) (e.g. 'He explained about the situation'.)

Interestingly, the first three of these four features for which there was no statistically significant change are ones for which there was already a high level of replacement by the standard form in the August test. Thus there was little room for 'improvement'.

Table 2 compares our students' performance to the results obtained by Gough (1996) and Makalela $(1998)^{2}$. Our August results (Test 1) were statistically further from the standard for seven of the constructions than were those in Gough's (1996) and Makalela's (1998) samples. These were:

- Use of the subordinators 'although...but...';

- 'Can be able to' as a phrasal equivalent of 'can';

- Question order retained in indirect questions;

- The construction ' $\mathrm{x}$ makes y to...';

- The construction 'tried that I might see her';

- Use of resumptive pronouns;

- Use of 'very much' as an intensifier.

In the case of two features, our students' performance was statistically the same as those obtained by Gough's (1996) and Makalela's (1998) students. These include:

- Topicalisation.

- Omission of 'a';

Finally, in only one case (marking of past tense), is our students' usage closer to standard norms than Makalela's (1998) students'.

By the October test, our students, while still further from SE than Gough's (1996) and Makalela's (1998) teachers, had moved closer to the standard form and their results were statistically equivalent to those of Gough's (1996) and Makalela's (1998) in the case of three further constructions:

- Use of subordinators 'although...but...'; 
- 'Can be able to' as a modal verb;

- The construction ' $\mathrm{x}$ makes y to...';

In addition, our students had shifted so that they were statistically closer to the SE norm than were Makalela's (1998) teachers in the case of topicalisation.

It is interesting that our students displayed less ability than Gough's (1996) and Makalela's (1996) subjects to rewrite sentences into SE. In both Makalela's and Gough's studies, the subjects were teachers (speakers of BSAE) who had completed their training and were already teaching. What may be inferred from this is firstly that they were older than our students, who had just finished school, and secondly that their post secondary education and interest (as English teachers) may have predisposed them to a greater sensitivity to the standard form. In addition, having to mark the work of their learners might also have had an effect.

An alternative explanation is that the greater deviation in our students from the standard norm reflects a stabilising of the Black South African English variety in a new generation of its speakers. However, given the short interval between Gough (1996) and Makalela's (1998) samples and ours, it is too early to draw this conclusion. The education, interest and experience of the practising English teachers compared to our students remains the more convincing reason for the difference observed. Repeated monitoring and sampling of the population of BSAE speakers in the future will be of value.

The results described above indicate that students were sensitised to some extent to the fact that of forms that they previously regarded as two acceptable options, only one is found in formal written academic contexts. These results suggest that such insights might benefit students if they could include in their repertoire a variety that came close to the norms considered appropriate for the purposes of academic writing. For this to happen two things are necessary. Firstly, students need to be able to distinguish the SE from the BSAE forms.

Secondly, it is important that students should not be alienated by what they might experience as a devaluing of an African variety in favour of a western or 'white' variety of English. An attitude to BSAE perceived by students as negative makes students feel like outsiders instead of speakers of one of a range of South African varieties who can, for formal written purposes, acquire a somewhat more standard form. It is important that students develop writing in an academic way as part of their identity / one of their identities. De Kadt and Mathonsi (2003) found that some African students in their study experienced having to write in the ways required by lecturers as suppressing or losing Africanness rather than as extending their identity to include an academic identity. Both De Kadt and Mathonsi (2003) and Rudwick (2004) found that English was not regarded by the participants as a large part of their identity. In De Kadt and Mathonsi (2003), students overwhelmingly identified 'writing with an African voice' as writing in an African language. The young isiZulu-speaking participants in Rudwick's study (2004) viewed English as of instrumental value only; they saw it as alien and as expressing 'white culture'. This lack of ownership is likely to be a barrier to students studying through the medium of English, and we wished to avoid reinforcing this perception of lack of ownership in the assignment we gave our students. 
The attitudes to BSAE of academic staff and the institution as a whole are also important. Some academic staff are adamant that only SE is acceptable in academic contexts. Less binary thinking seems necessary. The argument that SE should be taught in South African schools and universities that Wright (1996) presents relates to its appropriateness in particular domains like formal writing. A common argument in support of this (e.g. Titlestad 1996) is the importance of English as a language of international communication in the world of research. For general purposes outside of formal academic writing however, we believe that students' use of English is unlikely to change appreciably given the South African context, the situation in which our students have acquired English, and the fact that they are not in an immersion context with English speakers. It is a variety in which our students express interest and pride, and we regard it as important for reasons of identity.

It is interesting to note that students themselves do not devalue BSAE. Coetzee-Van Rooy and Van Rooy (2005) found that their black students viewed the acrolect form of BSAE as having the highest status out of a range of South African English varieties. This indicates that students preferred to associate themselves with this variety rather than their own mesolect BSAE or with any native speaker/'white' variety. Although their students used racial labels such as 'Black English' for language varieties, the most common label they applied to BSAE was South African English.

To sensitise students to differences between BSAE and SE and at the same time to avoid alienating students by stigmatising BSAE, the assignment students were given therefore represented BSAE as an emerging variety which is spoken by more people in South Africa than are the varieties of South African English that are spoken by native speakers of English. We hoped that learning about the differences between BSAE and SE in the context of this assignment and not in the context of grammar lessons would have a positive effect on acquisition of a formal written register. Students were very interested in the existence of BSAE, which they had previously regarded as the standard form of English, and some expressed pride and satisfaction in its existence. The following are examples of students' opinions as expressed in their reports. Some were against accepting BSAE for use in schools, viewing BSAE as 'errors' and a lowering of standards:

If English was to be taught in schools as BSAE, its standard would be lowered. We still have a chance to recognise those errors of BSAE and go for Standard English.

Students were also aware that SE carries benefits:

Making BSAE speaker to upgrade their speaking standards will lead to a prosperous life as English is the communicating language in the world.

Some support was expressed for accepting BSAE as a standard for South Africa. Contrary to the findings of De Kadt and Mathonsi (2003) and Rudwick (2004), a number of students viewed this variety of English as capable of expressing their culture and identity:

BSAE is the way which black people should speak as to represent their culture and where they are coming from. 
Accepting BSAE could give us identity and freedom of speech.

Black South African English is good for the fact that it reflects our background and originality, so BSAE can even be taught in schools as the second language.

A sense of ownership of BSAE is indicative of an identity as an English speaker, and may be an important step towards students' extending their repertoire to include a more formal written variety. More research is needed on this point.

\section{CONCLUSION}

Our data allow the stability of Black South African English forms to be assessed from two perspectives. Firstly, stability of these forms can be assessed from the perspective of the proportion of our sample of the population who can rewrite in the standard form a sentence containing the BSAE form. This involves student performance in the August test. Secondly, stability can be assessed with regard to the effectiveness of alerting speakers of BSAE to the difference between the standard form and the BSAE form in shifting them towards regarding the SE form as the standard. This involves a comparison between performance in the August and October tests.

From the first perspective most of the features of BSAE reflected in Table 1 are stable, as the majority of students do not recognise as non-Standard the BSAE form in the August test. For eight out of thirteen features in Table 1, more than half of the students regarded the BSAE form as standard when tested in August.

From the second perspective however, it is clear that these features are more fluid and less stable than the perspective above indicates. Table 1 shows a significant change in ability to recognise and rewrite BSAE features in nine out of thirteen features consequent on a relatively minor intervention. This indicates that BSAE is not yet a stable variety. Our research supports that of Van der Walt and Van Rooy (2002) which viewed BSAE as being in a transitional phase where both standard and non-standard forms are accepted.

A third perspective on this question of stability of Black South African English as a variety, which is not reflected in our study, would be the extent to which students produce the standard and BSAE forms in their own writing before and after the intervention. We intend to probe this aspect in future research.

\section{END NOTES}

${ }^{1}$ Use of the progressive with stative verbs (in BSAE) can be seen in terms of economy if it is regarded as simplifying a rule by removing the exception in which some verbs do not combine with the progressive. Stative verbs are verbs expressing states (such as 'believe'), which in SE are not likely to be realised in the progressive as they are identical from moment to moment and don't express temporary states or limited duration. By contrast with this analysis Van Rooy (2006) argues that the progressive form is used in BSAE to express a different meaning from the meaning it expresses in SE. In SE it expresses a temporary action in progress; in BSAE it is used to express the persistitive aspect, an aspect unique to Bantu languages, and which is used to express activity that started in the past and is presently on-going. 
${ }^{2}$ The z-test used to test significance took into account the fact that Gough's and Makalela's samples were very small (20 in each case), and found the difference to be significant in a number of cases.

$$
\mathrm{Z}=\frac{p_{1}-p_{2}}{s e_{p 1-p 2}}=\frac{p_{1}-p_{2}}{\sqrt{\hat{p}(1-\hat{p})\left(\frac{1}{n_{1}}+\frac{1}{n_{2}}\right)}}, \hat{p}=\frac{n_{1} p_{1}+n_{2} p_{2}}{n_{1}+n_{2}} \text { (Caulcott, 1973:xvii) }
$$

\section{REFERENCES}

2001 CENSUS. http://www.statssa.gov.za/census01/html/default.asp accessed 29th January 2007.

COETZEE-VAN ROOY, S \& B VAN ROOY. 2005. South African English: Labels, comprehensibility and status. World Englishes, 24(1):1-19.

COETZEE-VAN ROOY, AS \& MM VERHOEF. 2000. Perceptions of English proficiency: views from Southern Sotho speakers. South African Journal of Linguistics, Supplement 38:163-85.

DE KADT, E \& N MATHONSI. 2003. Writing in English with an 'African voice': Ownership, identity and learning. Journal for Language Teaching, 37(1):92-102.

DE KLERK, V. 1999. Black South African English: Where to from here? World Englishes, 19(3):311324.

DE KLERK, V. 2003a. Towards a norm in South African Englishes: The case for Xhosa English. World Englishes, 22(4):463-481.

DE KLERK V. 2003b. Xhosa English as an institutionalised variety of English. English World-Wide, 24(2):221-243.

DE KLERK, V. 2006 Corpus Linguistics and World Englishes: An Analysis of Xhosa English. London: Continuum.

GILL, SK. 1999. Standards and emerging linguistic realities in the Malaysian workplace. World Englishes, 18(2):215-32.

GOUGH, D. 1996. Black English in South Africa. In de Klerk V (Ed.), Varieties of English around the World: Focus on South Africa. Amsterdam: John Benjamins. 53-77.

KACHRU, B. 1992. World Englishes: Approaches, issues and resources. Language Teaching, 25:1-14.

MAKALELA, L. 1998. Institutionalized Black South African English. National Association of Educators of Teachers of English, 13:58-71.

MESTHRIE, R. Anti-deletions in an L2 grammar: A study of Black South African English mesolect. English World-Wide, 27(2):111-145. 
MCKENNA, S. 2004. The intersection between academic literacies and student identities. South African Journal of Higher Education. 18(3):269-280.

NWAILA, C. 1993. English in South Africa: The dilemma facing teachers. ELTIC Reporter, 17:3-10.

RUDWICK S. 2004. 'Zulu, we need [it] for our culture': Umlazi adolescents in the post-apartheid state. Southern African Linguistics and Applied Language Studies. 22(3\&4): 159-172.

SCHMIED, JJ. 1991. English in Africa: An introduction. Harlow, Essex: Longman.

TITLESTAD P. 1996. English, the constitution and the future. In De Klerk, V. Focus on South Africa. Amsterdam: John Benjamins. 163-173.

VAN DER WALT J \& B VAN ROOY. 2002. Towards a norm in South African Englishes. World Englishes, 21:113-28.

VAN ROOY, B. 2000 Introduction. South African Journal of Linguistics. 38:i-vii.

VAN ROOY, B. 2006. The extension of the progressive aspect in Black South African English. World Englishes, 25(1):37-64.

VAN ROOY, B. \& G VAN HUYSTEEN. 2000. The vowels of BSAE: Current knowledge and future prospects. South African Journal of Linguistics. 38:15-33

WADE, R. 1996 An investigation of the putative restandardisation of South African English in the direction of a "new" English, Black South African English. Unpublished M.A. dissertation. Durban: Natal University.

WILLIAMS J. 1987. Non-native varieties of English: A special case of language acquisition. English World-Wide 8: 161-99.

WRIGHT L. 1996. Standardisation and Black South African English. In De Klerk, V, Focus on South Africa. Amsterdam: John Benjamins. 149-162.

\section{BIOGRAHIC NOTE}

Jean Parkinson is a teacher of English for Specific Purposes in the Science Faculty of the University of KwaZuluNatal. Her research interests include English for Specific Purposes, literacy acquisition and the discourse of science. Email: Parkinson@ukn.ac.za

Vanessa Singh is a teacher of English for Specific Purposes in the Science Faculty of the University of KwaZuluNatal. Her research interests include Black South African English as a New English variety. Email: singhv2@kzn.ac.za 